\title{
The mental health needs of women detained in police custody
}

\section{David Scott, Sinéad McGilloway \& Michael Donnelly}

To cite this article: David Scott, Sinéad McGilloway \& Michael Donnelly (2009) The mental health needs of women detained in police custody, Journal of Mental Health, 18:2, 144-151, DOI: $10.1080 / 09638230701879193$

To link to this article: https://doi.org/10.1080/09638230701879193

曲 Published online: 06 Jul 2009.

Submit your article to this journal $\pi$

Џlll Article views: 159

Q View related articles ๘

4 Citing articles: 6 View citing articles ๘ 


\title{
The mental health needs of women detained in police custody
}

\author{
DAVID SCOTT ${ }^{1}$, SINÉAD MCGILLOWAY $^{2}, \&$ MICHAEL DONNELLY ${ }^{1}$ \\ ${ }^{1}$ Department of Epidemiology and Public Health, School of Medicine and Dentistry, Queen's University, \\ Belfast, and ${ }^{2}$ Department of Psychology, National University of Ireland at Maynooth, Ireland
}

\begin{abstract}
Background: This paper describes and appraises the work of a city centre Criminal Justice Liaison and Diversion (CJLD) service in relation to contact with female Mentally Disordered Offenders (MDOs). Aims: To describe the population of female detainees referred to the service by examining administrative outcomes and psychiatric assessment data.

Method: Two Community Mental Health Nurses (CMHNs) collected information on the mental health needs and service utilization of MDOs over a three-year period. Information on psychiatric history, offending history and recommended follow-up services is also presented.

Results: One-in-five (217/1089) detainees assessed by the service were female, $91 \%$ of whom had a mental illness. Two-thirds were "cases" on the GHQ whilst $58 \%$ attained "above threshold" BPRS scores; $43 \%$ and $54 \%$ respectively had a history of harming others or themselves. Most had previous contact with mental health services. The majority (59\%) were referred to their GPs following assessment.

Conclusions: Many women with mental illness are arrested and detained in police custody. The CJLD service effectively identified, assessed and linked the majority of female MDOs to services.

Declaration of interest: None.
\end{abstract}

Keywords: Mental disorder, women offenders, diversion, liaison

\section{Introduction}

Recent reports highlight the increasing number of sentenced female prisoners and women on remand (Home Office, 2004). This increase is noteworthy when compared to the much smaller (though still significant) increase in male prisoners (Home Office, 2004). Many women detainees experience mental illness and would benefit from services (e.g., DoH, 2004). The aim of the UK government is to ensure that offenders with mental illness are identified and treated and this is reflected in policy (e.g., Home Office, 2004; DoH, 2004).

Diverting MDOs away from the Criminal Justice System (CJS) into Health and Social Services (H\&SS) care has been UK government policy for some time (e.g., Home Office, 1990; Circular 66/90). Diversion services vary considerably, but share core functions (e.g., identifying MDOs, providing assessments and, facilitating access to treatment). However, few services have been evaluated and little is known, about their effectiveness in meeting the needs of female MDOs. This study sought to: estimate the number of women MDOs 
detained in a regional, city centre police station; describe their mental health needs and assess the response of the CJS to them.

The service comprises a screening and mental health assessment plus a mechanism for referral to H\&SS. The service is located in a Police Station in central Belfast and is provided by two CMHNs supported by forensic psychiatry.

Currently, under Police and Criminal Evidence Order Northern Ireland (1989) legislation, detainees complete an initial risk assessment with a Custody Sergeant this helps identify any possible physical or mental health problem that may require a FMO examination. If mental illness is suspected, the sergeant refers the detainee to the CJLD service. The service also accepts referrals from other concerned professionals or family members. In addition the CMHNs screen the Custody Record Forms (CRFs) of nonreferred detainees to identify potential MDOs who otherwise would not have been identified. The CMHNs use four criteria when screening the CRFs: (i) history of mental illness/learning disability; (ii) an "odd" crime; (iii) violent crime; and (iv) unusual behaviour which alerted the police. All "identified" detainees are asked to participate in an assessment, after which a psychiatric report is provided to the court, arresting officer and solicitors.

\section{Method}

The assessment comprises a battery of measures, used extensively with MDOs.

(1) A Profile Form (PF) is completed with all participating detainees. This measure collects socio-demographic and other key information including probable diagnosis, institutional and offending history, and suggested follow-up services.

(2) The Screening Questionnaire (SQ) comprises two questions to identify depressive symptoms (Whooley et al., 1997). The SQ also contains the Psychosis Screening Questionnaire (Bebbington \& Nayani, 1995) designed to identify possible psychosis.

(3) Detainees are screened for learning disability using the four-item Learning Disability Questionnaire (LDQ) (Lyall et al., 1995).

(4) An Assessment of Risk (AOR) (Hare, 1980) questionnaire is completed. This comprises: (i) a checklist of selected items based on standard risk assessment guides; (ii) eight questions about attitude to harming self or others; and (iii) the Dangerous Behaviour Checklist adapted from the Problems Questionnaire (Clifford, 1987) in which five "core" risk-related behaviours (e.g., tendency to violence) are rated.

(5) The 18-item Brief Psychiatric Rating Scale (BPRS, Overall \& Gorham, 1962) is completed. Total scores indicate a possible diagnosis of schizophrenia or severe affective disorder.

Participants complete three self-report measures: (a) the 12-item General Health Questionnaire (GHQ) (Goldberg, 1978), a measure of minor psychiatric morbidity; (b) the AUDIT questionnaire (Saunders et al., 1993), measures harmful alcohol consumption; and (c) the DAST questionnaire (Skinner, 1982) assesses drug misuse.

\section{Results}

Profile of offenders

During the three year study, 9014 people were detained in the police station where the service is based. Assessments were completed on $12 \%$ of detainees (1089/9014). One in five 
of those assessed were female $(20 \%, 217 / 1089)$. The majority of assessed females were referred by the FMO $(43 \%, 94 / 217)$; one-third $(34 \%, 72 / 217)$ were identified through CRF screening; almost one in five were referred by police officers $(18 \%, 38 / 217)$.

Almost half of the females assessed were single; most were unemployed and in their early $30 \mathrm{~s}$ (mean $=34, \mathrm{SD}=11.74$, range $=49)$. Almost one-third had one or more children $(30 \%, 66 / 217)$, many of whom were lone parents $(41 \%, 27 / 66)$. Approximately one quarter lived alone, although many also lived with their spouse/partner or their spouse/partner and children. More than one in ten were homeless or living in hostel accommodation. Homeless detainees were significantly younger $($ mean $=30.18, \mathrm{SD}=8.37$ ) than other detainees (mean $=34.97, \mathrm{SD}=12.17 ; t(1,112)=-2.82, p=.006)$. Over half had an institutional history including $41 \%(89 / 217)$ who had previously received psychiatric inpatient care (see Table I).

Three-quarters of female detainees $(76 \%, 164 / 217)$ used mental health medication when arrested. A similar proportion had previously seen one or more mental health professional(s) including a psychiatrist $(58 \%, 127 / 217)$, Community Psychiatric Nurse $(22 \%, 47 / 217)$, and social worker $(20 \%, 43 / 217)$.

Half had a criminal history $(49 \%, 107 / 217)$, with many having two or more previous convictions $(37 \%, 81 / 217)$. More than one in ten had previously received a custodial sentence $(11 \%, 24 / 217)$. Most current offences were 'minor' with over half $(52 \%, 114 / 217)$

Table I. Characteristics of female detainees $(n=217)$.

\begin{tabular}{|c|c|c|}
\hline & Number & $\%$ \\
\hline \multicolumn{3}{|l|}{ Marital status } \\
\hline Single & 103 & 48 \\
\hline Married/Co-habiting & 53 & 24 \\
\hline Divorced/separated & 50 & 23 \\
\hline Other $^{1}$ & 11 & 5 \\
\hline \multicolumn{3}{|l|}{ Living situation } \\
\hline Alone & 49 & 23 \\
\hline Spouse/partner \& children & 34 & 16 \\
\hline Spouse/partner & 29 & 13 \\
\hline Lone parent & 26 & 12 \\
\hline Parents & 23 & 11 \\
\hline Friends/extended family & 21 & 10 \\
\hline No fixed abode & 20 & 9 \\
\hline Hostel/shared accommodation & 15 & 7 \\
\hline \multicolumn{3}{|l|}{ Employment status } \\
\hline Unemployed & 180 & 83 \\
\hline Full-time & 19 & 9 \\
\hline Other ${ }^{2}$ & 15 & 7 \\
\hline Part-time & 3 & 1 \\
\hline \multicolumn{3}{|l|}{ Institutional history $^{3}$} \\
\hline No institutional history & 98 & 45 \\
\hline Psychiatric hospital & 89 & 41 \\
\hline Prison/penal institution & 24 & 11 \\
\hline Not known & 21 & 10 \\
\hline "Care" background & 11 & 5 \\
\hline
\end{tabular}

1“'Other” includes; widowed ( $n=8)$ and unknown $(n=3)$;

2“'Other" includes; unknown $(n=5)$, higher education $(n=4)$ and retired $(n=2)$;

${ }^{3} 25$ detainees had two or more institutional placements. 
being acquisitive (e.g., theft) and more than one-in-ten (36/217) involving a public order offence (e.g., disorderly conduct). However, many (48/217) involved an offence against another person (e.g., assault). Approximately half of current offences (48\%, 104/217) were committed while under the influence of alcohol or drugs. Furthermore, almost three-quarters of detainees $(72 \%, 157 / 217)$ displayed one or more problem behaviour(s) prior to detention, e.g., physical and/or verbal aggression (31\%,68/217) and self-harm $(33 / 217,15 \%)$.

\section{Assessment and referral}

Ninety-one percent of those assessed (198/217) had a mental illness. Common diagnoses included: depression $(61 \%, 133 / 217)$; alcohol and/or drug-related problems $(23 \%, 49 / 217)$; anxiety state $(9 \%, 19 / 217)$; personality disorder $(9 \%, 19 / 217)$; and schizophrenia (3\%, $7 / 217)$. The majority $(82 \%, 178 / 217)$ experienced depression during the previous month; psychotic symptoms were reported in all but 28 cases (13\%). Ten detainees had a possible learning disability.

Many detainees scored above the "cut-off" indicating "caseness" on both the GHQ $(66 \%, 143 / 217)$ and the BPRS (58\%, 125/217 (see Table II)). BPRS caseness was unassociated with age though GHQ "cases" were significantly older (mean $=35.75$, $\mathrm{SD}=11.71)$ than non-cases (mean $=30.15, \mathrm{SD}=10.82 ; t(192)=-3.01, p=.003)$. Almost half $(46 \%, 58 / 125)$ of BPRS cases were identified and referred by FMOs while the CMHNs identified an additional 28\% (35/125) of BPRS cases; police officers referred $18 \%(23 / 125)$ for assessment. The remainder were referred by magistrates or solicitors $(7 \%$, 9/125). Mean BPRS scores were above the clinical threshold of 9 (mean $=15.72$, $\mathrm{SD}=10.71$ ) indicating high levels of psychiatric disorder. BPRS “caseness" was unassociated with previous self-harm or causing harm to others. More than two-thirds of BPRS cases $(71 \%, 89 / 125)$ were also identified as "cases" on the GHQ $\left(\chi^{2}=7.022, \mathrm{df}=1\right.$, $p=.008)$. More than one-third of detainees $(39 \%, 84 / 217)$ consumed hazardous amounts of alcohol, although fewer reported drug use problems (17\%, 38/217). BPRS and AUDIT caseness were significantly associated $\left(\chi^{2}=.4331, \mathrm{df}=1, p=.037\right)$, although no significant associations were found between BPRS and DAST scores or between GHQ and either AUDIT or DAST scores. Detainees who abused alcohol were also more likely to abuse drugs $\left(\chi^{2}=11.16, \mathrm{df}=1, p=.001\right)$.

Many detainees showed evidence of psychopathic traits (e.g., callousness, 29\%, 64/217) and characteristics predictive of dangerous behaviour (e.g., substance abuse, 49\%,

Table II. Summary scores on mental health measures.

\begin{tabular}{|c|c|c|c|c|}
\hline Instrument & Mean Score & $\mathrm{SD}$ & $\begin{array}{l}\text { Minimum \& maximum } \\
\text { scores attained }\end{array}$ & $\begin{array}{l}\text { Number (\%) scoring } \\
\text { above cut-off }\end{array}$ \\
\hline $\begin{array}{l}\text { BPRS } \\
(n=189)\end{array}$ & 15.72 & 10.71 & $0-57$ & $\begin{array}{l}67 \text { (31) "possible case" } \\
58 \text { (27) "definite case" }\end{array}$ \\
\hline $\begin{array}{l}\text { GHQ } \\
(n=196)^{1}\end{array}$ & 8.61 & 5.01 & $0-12$ & $143(66)$ \\
\hline $\begin{array}{l}\text { AUDIT } \\
(n=189)\end{array}$ & 11.97 & 12.25 & $0-40$ & $84(39)$ \\
\hline $\begin{array}{l}\text { DAST } \\
(n=190)\end{array}$ & 2.42 & 4.97 & $0-20$ & $38(18)$ \\
\hline
\end{tabular}

${ }^{1} 63 \%(123 / 196)$ obtained the maximum score of 12 . 
107/217). Many had harmed others $(43 \%, 93 / 217)$ while more than half $(54 \%, 117 / 217)$ had self-harmed. Having a previous institutional history was associated with both self-harm $\left(\chi^{2}=31.49, \mathrm{df}=1, p=.001\right)$ and harming others $\left(\chi^{2}=8.55, \mathrm{df}=1, p=.003\right)$. More than one quarter $(28 \%, 61 / 217)$ had both self-harmed and caused harm to others. Harming others was associated with alcohol misuse $\left(\chi^{2}=39.06, \mathrm{df}=1, p=.001\right)$ and drug abuse $\left(\chi^{2}=4.42\right.$, $\mathrm{df}=1, p=.035)$. Self-harm was also associated with alcohol misuse $\left(\chi^{2}=20.61, \mathrm{df}=1\right.$, $p=.001)$ and drug abuse $\left(\chi^{2}=10.24, \mathrm{df}=1, p=.001\right)$. A substantial proportion $(44 \%, 95 /$ 217 ) was assessed as having violent tendencies, albeit of a mainly mild or minor nature (69/ 217). Global ratings of dangerousness indicated that $41 \%(90 / 217)$ were not a serious risk to themselves and/or others; $26 \%$ (57/217) posed a "moderate" risk (57/217) whilst more than one in ten represented a serious risk (23/217). One third of the group (71/214) also reported suicidal pre-occupations which was significantly associated with: alcohol misuse $\left(\chi^{2}=12.48\right.$, $\mathrm{df}=1, p=.001)$; drug abuse $\left(\chi^{2}=4.23, \mathrm{df}=1, p=.038\right)$; BPRS caseness $\left(\chi^{2}=11.92\right.$, $\mathrm{df}=1, \mathrm{p}=.001)$; previous self-harm $\left(\chi^{2}=68.31, \mathrm{df}=1, p=.001\right)$; harming others $\left(\chi^{2}=12.96, \mathrm{df}=1, p=.001\right)$ previous use of psychiatric services $\left(\chi^{2}=23.24, \mathrm{df}=1\right.$, $p=.001)$; and living alone and unsupported $\left(\chi^{2}=11.79, \mathrm{df}=5, p=.038\right)$.

Following assessment, detainees were typically referred to their GPs (59\%, 128/217), community addiction services $(19 \%, 41 / 217)$ and the community mental health team (CMHT) $(15 \%, 32 / 217)$ (see Table III). Police outcomes indicated that the majority of female detainees were charged and released on bail (35\%) or charged and detained (20\%). More than one in ten $(11 \%, 23 / 217)$ were diverted from the CJS due to the CJLD service's mental health report. Information on court "disposal" was available for $69 \%(149 / 217)$ of detainees, most of whom were remanded on bail to the community $(65 \%, 97 / 149)$, or remanded in custody $(10 \%, 15 / 149)$.

\section{Discussion}

The number of female offenders is rising as is the number of female detainees with mental disorder (O'Brien et al., 2003; DoH, 2004). Recent studies show that many imprisoned women experience mental health problems and would benefit from appropriate treatment

Table III. Recommended follow-up service(s).

\begin{tabular}{lrr}
\hline Type of service(s) $^{1}$ & Number & $\%$ \\
\hline Education advice and support $^{2}$ & 190 & 88 \\
Formal contact with GP & 69 & 32 \\
Suggest "self-refer" to GP $^{3}$ & 59 & 27 \\
Other $^{3}$ & 43 & 20 \\
Direct to community addiction services & 41 & 19 \\
Direct to Community Mental Health Team & 32 & 15 \\
Continue with existing services & 28 & 13 \\
Voluntary outpatient treatment & 12 & 5 \\
No recommendation & 11 & 5 \\
Compulsory admission to hospital & 6 & 3 \\
Refuses assistance/indifferent to help & 5 & 2 \\
Informal admission to hospital & 4 & 2 \\
Missing information & 4 & \\
\hline
\end{tabular}

\footnotetext{
${ }^{1} 190$ people ( $\left.88 \%\right)$ were directed to more than one service. Therefore, percentages do not sum to 100 .

${ }^{2}$ This is often provided by the CMHN at the time of the assessment and, if required, on subsequent occasions.

3، Other" includes "self-refer to psychology services", "forensic clinic" and "assess in hospital/prison hospital".
} 
(Prison Reform Trust, 2004). The need to provide gender sensitive services within the CJS is recognized at governmental level (e.g., Home Office, 2004); this policy recommends that female offenders with mental health problems be treated, where possible, in the community. CJLD schemes provide an ideal mechanism by which female MDOs may be identified and, where possible be diverted to receive treatment in the community. However, the extent to which these schemes respond specifically to the needs of female offenders is unknown. This study sought to determine if CJLD schemes are an appropriate way to identify, assess and divert female MDOs to appropriate services.

Our findings indicate that, most MDOs are male however, one in five of those assessed by the CJLD service were female, most of whom have potentially complex mental health difficulties. The referral and screening process seem appropriate in that $91 \%$ of women assessed were deemed to have a mental illness; this compares favourably with the $85 \%$ and 90\% identified by other police station-based schemes in England and Wales (James, 1999; Riordan et al., 2000). Previous research has shown high levels of mental disorder in female sentenced prisoners (O’Brien et al., 2003; Prison Reform Trust, 2004) especially among single women (Badger et al., 1999). The recorded diagnoses in this study, together with GHQ results indicate high levels of depression and psychiatric morbidity, which are consistent with the traditionally higher incidence of affective disorder and neuroses among female offenders (e.g., Sue et al., 1991). Diagnostic information in this study was provided by both FMOs and CMHNs. Ideally, a forensic psychiatrist should have provided this information but this would not reflect "normal" practice within the CJLD service.

Whilst most women were referred to the service by the FMO, many were identified through CRF screening. This supports the validity of the systematic screening procedure used by the CMHNs. Furthermore, many "severe cases" (as indicated by the BPRS) were identified by the CMHN screening or police officers. This highlights the benefits of CRF screening and underlines the importance of providing mental health awareness training for police officers.

It is surprising that many female MDOs were not identified by the FMO. However, currently FMOs do not assess all detainees; the custody sergeant first completes a risk assessment then decides if a medical examination is appropriate. Again, this highlights the need for comprehensive mental health training for custody staff. A further complication for both FMOs and custody staff in the identification of MDOs relates to the potentially concealing effects of alcohol and drug abuse and the typically high levels of depression in this population (Rice \& Harris, 1997). The importance of accurately identifying MDOs is illustrated by the fact that, in the absence of this service, many vulnerable women may have passed through the CJS without receiving any care. This is particularly problematic for the one third of women who have complex needs relating to suicidal preoccupation. The prevalence of suicidal preoccupation described here is similar to that reported by O'Brien et al. (2003) who found that $23 \%$ of women remand prisoners had thought about suicide in the previous week while $25 \%$ had attempted suicide in the previous year. These findings suggest that prison may not represent a suitable option for female MDOs at risk of attempting suicide.

Another important finding pertains to the large number of women who had previous contact, with mental health services. This appears to have had little impact on their current mental health status, or their ability to avoid criminal behaviour. Similarly, it is not known if other detainees have experienced difficulty in accessing mental health services. This may be particularly the case for women who are homeless and whose mental health is possibly not a priority when compared to other everyday needs. The CJLD service provides a means of connecting these women to health and social services. 
A recurring problem is the link between offending and alcohol or drug abuse. This study found that alcohol, in particular, was related to criminal behaviour and is an important risk factor for women who exhibited a more serious psychiatric disorder, a tendency to self-harm and/or suicidal pre-occupation. The extent of drug use in the current study is low when compared to other studies of women offenders in the UK (e.g., Brooke et al., 1998). This may be due, at least in part, to the typically lower levels of drug misuse in NI (DHSS (NI), 2005). We also recognize that detainees may have provided socially desirable responses.

Our findings indicate that many women regularly consume harmful levels of alcohol, and to a lesser extent, drugs. However, few were referred to community addiction services. This may be due to current pressures on this service and the need to manage more severe cases. However, the unwillingness of detainees to engage with this service may have influenced referral patterns, as the service will only treat those who desire help. Although engaging female offenders in treatment programmes has proved problematic, the benefits of treatment have been demonstrated both in terms of improving mental health and reducing recidivism (Dowden \& Blanchette, 2002).

Many women in the current study were well known to psychiatric and CJS services. However, these services do not appear to intervene effectively with this group, some of whom have complex needs. Indeed, it is the multiplicity of these women's needs that poses the greatest challenge for service providers. Nonetheless, the overarching aim of any existing, or new service should be the appropriate and timely management and treatment of offenders coupled with a reduction in offending. This can only be achieved through a more flexible, co-ordinated and integrated service response, ideally within the context of a mainstream community forensic mental health service.

The CMHNs routinely provide information, advice and support to assessed detainees and recommend appropriate follow-up service(s). The nurses also co-ordinate follow-up care and provide ongoing advice and support to offenders, the police and health care professionals. Importantly, GPs were the most common referral agent, reflecting their pivotal role within health and social services. This is important given that females are more likely to attend their GP than males. Therefore, GPs could be targeted in the development of new initiatives aimed at female MDOs in particular. Many women in our study had children and the impact of their detention on their children is difficult to quantify. Little research exists relating to the impact of parenthood on female offending and a consensus has yet to be reached. For example, Bogart et al. (2005) reported that most female drug-using offenders were mothers whilst Bent (2005) found that for many female offenders, parenthood was associated with lower rates of recidivism. No studies appear to have looked at the long-term implications in terms of the overall development and general welfare of these young people. This may be particularly important for the $10 \%$ of women in our study who are lone parents.

Fewer detainees than expected were referred to the Community Mental Health Team. This re-emphasizes the need to expand community-based service options currently available to the CJLD scheme, and/or to develop gender-sensitive initiatives (Home Office, 2004). An examination of police and court disposals illustrated that the majority of female MDOs were returned to the community. Thus, there exists an opportunity to target and treat many women who have been identified by the CJLD service in the community.

This study provided an opportunity to describe a CJLD service and collate information relating to female MDOs. This information is important for policy and practice as little empirical evidence exists to support the continued role, efficacy and development of CJLD services in the UK and elsewhere (James, 1999; Skipworth \& Humberstone, 2002). However, the study was necessarily descriptive and little data on follow-up is provided (although most of the women returned to the community). Furthermore, a comparison of 
male and female offenders, whilst interesting, was not a focus of the study. Notably, we are currently conducting a comparative follow-up study of the Belfast-based CJLD service that should allow us to address some of the limitations of the current study.

\section{Acknowledgements}

We would like to thank the two CMHNs, Brenda Scullion and Noel McDonald, for their help throughout the study and the NHS National R\&D Programme on Forensic Mental Health who fund David Scott. The views expressed are those of the authors.

\section{References}

Badger, D., Nursten, J., Williams, P., \& Woodward, M. (1999). Systematic review of the international literature on the epidemiology of Mentally Disordered Offenders. York: NHS Centre for Reviews and Dissemination, University of York.

Bebbington, P., \& Nayani, T. (1995). The psychosis-screening questionnaire. International fournal of Methods in Psychiatric Research, 5, 11-19.

Bent, B. (2005). Gender differences in life course theory of recidivism. International fournal of Offender Therapy and Comparative Criminology, 49(3), 325-342.

Bogart, J., Stevens, S., et al. (2005). Criminally involved drug using mothers: The need for system change. Prison fournal, 85(1), 65-82.

Brooke, D., Taylor, C., Gunn, J., \& Maden, A. (1998). Substance misusers remanded to prison - a treatment opportunity? Addiction, 93(12), $1851-1856$.

Clifford, P. (1987). The Problems' Questionnaire. London: Research and Development for Psychiatry.

Department of Health (2004). Mainstreaming gender and women's mental health. London: HMSO.

Department of Health and Social Services (Northern Ireland) (2005). Drug use in Ireland E Northern Ireland 2002/ 2003; Drug Prevalence Survey. Bulletin Two. Belfast: DAIRU.

Dowden, C., \& Blanchette, K. (2002). An evaluation of the effectiveness of substance abuse programming for female offenders. International fournal of Offender Therapy and Comparative Criminology, 46(2), 220-230.

Goldberg, D. (1978). Manual of the General Health Questionnaire. Windsor: NFER-Nelson.

Hare, R. D. (1980). A research scale for the assessment of psychopathy in criminal populations. Personality and Individual Differences, 1, 111-119.

Home Office (1990). Provision for mentally disordered offenders. (Circular 66/90) London: Home Office.

Home Office (2004). Women's Offending Reduction Programme. London: Home Office.

James, D. (1999). Court Diversion at 10 years: Can it work, does it work and has it a future? Fournal of Forensic Psychiatry, 4, 575-581.

Lyall, I., Holland, A. J., Collins, S., \& Styles, P. (1995). Incidence of persons with a learning disability detained in police custody: A needs assessment for service development. Medicine Science and the Law, 35, 61-71.

O'Brien, M., Mortimer, L., et al. (2003). Psychiatric morbidity among women prisoners in England and Wales. International Review of Psychiatry, 15(1), 153-157.

Overall, J. E., \& Gorham, D. R. (1962). The brief psychiatric rating scale. Psychological Reports, 10, $799-812$.

Prison Reform Trust (2004). Lacking conviction: The rise of the women's remand population. London: Prison Reform Trust.

Rice, M. E., \& Harris, G. T. (1997). The treatment of mentally disordered offenders. Psychology, Public Policy and the Law, 3, 126-183.

Riordan, S., Wix, S., \& Kenny-Herbert, J. (2000). Diversion at the point of arrest: Mentally disordered people and contact with the police. Fournal of Forensic Psychiatry, 111, 683-690.

Saunders, J. B., Aasland, O. G., Babor, T. F., et al. (1993). Development of the Alcohol Use Disorders Identification Test (AUDIT): WHO collaborative project on early detection of persons with harmful alcohol consumption. Addiction, 88, $791-804$.

Skinner, H. A. (1982). The Drug Abuse Screening Test. Addictive Behaviours, 7, 363-371.

Skipworth, J., \& Humberstone, V. (2002). Community forensic psychiatry: Restoring some sanity to forensic psychiatric rehabilitation. Acta Psychiatrica Scandinavica, 106(Suppl. 412 June), 47-53.

Sue, D., Sue, D. W., \& Sue, S. (2003). Understanding Abnormal Behavior. Boston: Houghton Mifflin Company.

Whooley, M. A., Avins, A. L., Miranda, J., et al. (1997). Case-finding instruments for depression. Two questions are as good as many. Fournal of General Internal Medicine, 12, 439-445. 